\title{
Inactivation of coronaviruses during sample preparation for proteomics experiments
}

Marica Grossegesse ${ }^{1, \#, *}$, Paula Leupold ${ }^{1,4, \#}$, Joerg Doellinger ${ }^{2}$, Lars Schaade $^{3}$ and Andreas Nitsche ${ }^{1}$

${ }^{1}$ Robert Koch Institute, Centre for Biological Threats and Special Pathogens, ZBS 1: Highly Pathogenic Viruses, Seestr. 10, 13353, Berlin, Germany

${ }^{2}$ Robert Koch Institute, Centre for Biological Threats and Special Pathogens, ZBS 6: Proteomics and Spectroscopy, Seestr. 10, 13353, Berlin, Germany

${ }^{3}$ Robert Koch Institute, Centre for Biological Threats and Special Pathogens, Seestr. 10, 13353, Berlin, Germany

${ }^{4}$ Present address: Freie Universitaet Berlin, Institute of Chemistry and Biochemistry, Thielallee 63, 14195, Berlin, Germany

\# The authors contributed equally

${ }^{*}$ Corresponding author: grossegessem@rki.de, +49 30-18754-2140

\section{Table of Contents}

Table S1: Real-time PCR primer and probe sequences (S-2)

Table S2: Reaction mix for the one-step real-time PCR using AgPath-I One-step RT-PCR Kit (S-2)

Table S3: Thermal profile for real-time PCR (S-2)

Table S4: Final viral titres used for inoculation in the inactivation study (S-2)

Table S5: $\mathrm{C}_{\mathrm{T}}$ values after lysis buffer inactivation and three consecutive blind passages as determined by real-time PCR (S-3) 
Table S1: Real-time PCR primer and probe sequences.

\begin{tabular}{|c|c|}
\hline Name & Sequence \\
\hline 229E forward & TAC CAC ACT TCA ATC AAA AgC TCC \\
\hline $229 \mathrm{E}$ reverse & CgA CTC TgC gAC CTC gAC T \\
\hline 229E probe & 6-FAM-CAC ggg AgT Cag gTT C-MGB \\
\hline OC43 forward & CCA CTT gTg gTC ATg TTT ATg AAg TA \\
\hline OC43 reverse & TgC ACT CTT AgT ATg CAA TAC Agg gT \\
\hline OC43 probe & 6-FAM-ATT TgA TAg CAC AAT CTT-MGB \\
\hline
\end{tabular}

Table S2: Reaction mix for the one-step real-time PCR using AgPath-ID ${ }^{\mathrm{TM}}$ One-step RT-PCR Kit.

\begin{tabular}{|l|r|}
\hline Reagent & Volume/reaction $[\boldsymbol{\mu L}]$ \\
\hline RNase-free water & 6.00 \\
\hline $2 \times$ RT-PCR buffer & 12.50 \\
\hline Forward primer $(10 \mu \mathrm{M})$ & 1.00 \\
\hline Reverse primer $(10 \mu \mathrm{M})$ & 1.00 \\
\hline Probe $(10 \mu \mathrm{M})$ & 0.50 \\
\hline $25 \times$ RT-PCR Enzyme Mix & 1.00 \\
\hline Master mix & 22.0 \\
\hline Sample & 3.0 \\
\hline
\end{tabular}

Table S3: Thermal profile for real-time PCR.

\begin{tabular}{|c|c|c|}
\hline Time [s] & Temperature & Number of cycles \\
\hline 900 & 45 & 1 \\
\hline 600 & 95 & 1 \\
\hline 95 & 15 & 45 \\
\hline 60 & 45 & \\
\hline
\end{tabular}

Table S4: Final viral titres used for inoculation in the inactivation study.

\begin{tabular}{|l|c|c|}
\hline \multirow{2}{*}{} & \multicolumn{2}{|c|}{ Virus titre [PFU/mL] } \\
\cline { 2 - 3 } & $\mathbf{O C 4 3}$ & $\mathbf{2 2 9 E}$ \\
\hline SDS, GdmCI & $1.4 \times 10^{3}$ & $5.5 \times 10^{2}$ \\
\hline SDC, Urea & $1.4 \times 10^{4}$ & $5.5 \times 10^{3}$ \\
\hline TFA & $1.7 \times 10^{3}$ & $6.9 \times 10^{2}$ \\
\hline Heat only (5 ${\left.\text { min at } 95^{\circ} \mathbf{C}\right)}^{2}$ & $7.0 \times 10^{5}$ & $2.8 \times 10^{5}$ \\
\hline
\end{tabular}


Table S5: $\mathrm{C}_{\mathrm{T}}$ values after lysis buffer inactivation and three consecutive blind passages as determined by real-time PCR. RT: room temperature.

\begin{tabular}{|l|l|}
\hline \multicolumn{2}{|c|}{ HCoV-OC43 } \\
\hline Sample & $\mathbf{C}_{\mathbf{T}}$ (average) \\
\hline Negative control & N/A \\
\hline GdmCl, RT & 36.45 \\
\hline Urea, RT \#1 & 35.07 \\
\hline Urea, RT \#2 & 34.12 \\
\hline
\end{tabular}

\begin{tabular}{|l|l|}
\hline \multicolumn{2}{|c|}{ HCoV-229E } \\
\hline Sample & C $_{\text {T }}$ (average) \\
\hline Negative control & N/A \\
\hline GdmCl, RT & N/A \\
\hline TFA, RT & N/A \\
\hline TFA, $95^{\circ} \mathrm{C}$ & N/A \\
\hline
\end{tabular}

